\title{
STUDIES OF NATURAL POPULATIONS OF MUS. I. BIOCHEMICAL POLYMORPHISMS AND THEIR BEARING ON BREEDING STRUCTURE ${ }^{1}$
}

\author{
Michael. L. Petras ${ }^{2}$ \\ Mammalian Genetics Center, Department of Zoology, The University of Michigan
}

Received December 2, 1965

Although the house mouse (Mus musculus L.) has received considerable attention from both the ecologist and the geneticist, very little information is available about genetic aspects of natural Mus musculus populations. Reasons for the paucity of such information are without doubt numerous. One which became obvious early in the current study is that most of the genetic variants known in the house mouse were discovered and studied in mice bred in the laboratory, under highly protective conditions. These same variants do not exist with any high frequency under more stringent conditions of the natural environment and so are of little value in the investigations of genetic aspects of natural populations. Only three systems have given any information about genetic parameters in natural populations of Mus musculus: (1) the agouti locus (Philip, 1938; Engels, 1948), (2) the $T$ locus (Dunn, 1957a, $b$; Dunn and Suckling, 1956; Lewontin and Dunn, 1960) and (3) discontinuous skeletal variants (Gruneberg, 1952; Weber, 1950; Deol, 1958; Berry, 1963).

Of these, the first is relatively straightforward, and has given some evidence, unfortunately very limited and conflicting, about breeding structure in the house mouse. The $T$ locus is likewise of limited value in this respect because of the number of complications involved (e.g., homozygous lethality, high transmission ratio of $t$-bearing sperm in heterozygous males, the vari-

\footnotetext{
${ }^{1}$ Portion of a dissertation submitted in partial fulfillment of the requirements for the degree of Doctor of Philosophy in the Rackham School of Graduate Studies of The University of Michigan.

${ }^{2}$ Present address: Department of Biology, University of Windsor, Windsor, Ontario.
}

ety of $t$-alleles). The investigations of skeletal variants are concerned primarily with the frequencies of such characters in various populations and the subsequent comparison of populations, and so, also, give little information about genetic parameters of natural populations.

Since feral house mice show limited variability in phenotypes readily detectable and useful in the study of genetic aspects of natural populations, attention was turned to electrophoretic patterns of a number of proteins. Four biochemical systems, which are known to have electrophoretic patterns controlled primarily by two alleles at a single autosomal locus, were examined. These are: (1) a prealbumin serum esterase component, (2) hemoglobin, (3) albumin-associated esterase, and (4) serum transferrin.

In those systems where feasible, i.e., prealbumin serum esterase and hemoglobin, estimates of allelic and zygotic frequencies were calculated. A comparison between the zygotic frequencies observed and those expected under a Hardy-Weinberg equilibrium, that is under a system of random mating, revealed a numerical deficiency of heterozygotes. An examination of the obvious explanations for this deficiency revealed population subdivision into small isolates as the most plausible. The genetically effective size of such isolates and the rate of genetic exchange between these isolates were estimated both from genetic and ecologic data.

\section{Sampling Localities}

Extensive trapping was carried out, in and around farm buildings in southeastern Michigan (Washtenaw County), during 


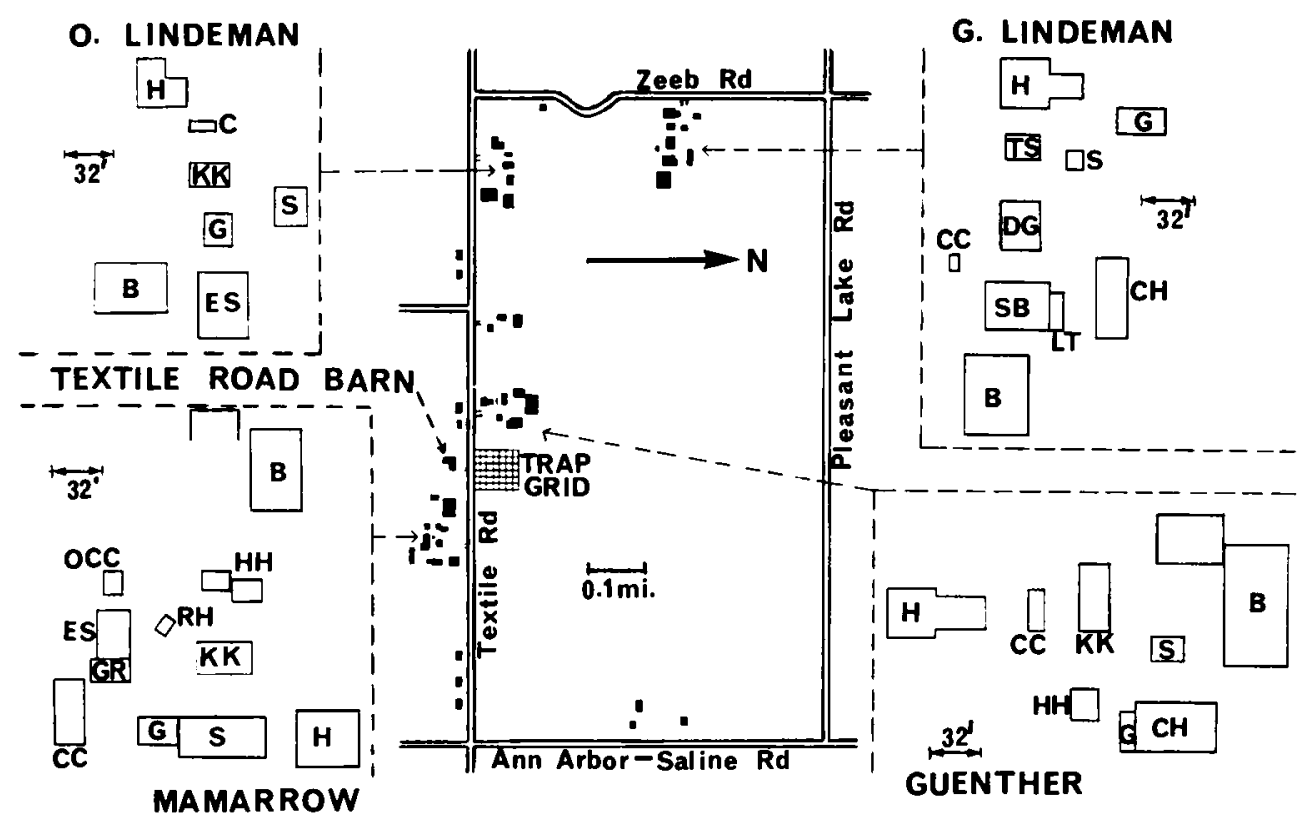

FIG. 1. Five collecting sites six miles southwest of Ann Arbor, Michigan. The sixth site, Gibbs Farm, is eight miles east of the above sites. Abbreviations: $\mathrm{B}$, barn; $\mathrm{C}$, small crib; $\mathrm{CC}$, chicken coop; $\mathrm{CH}$, chicken house; DG, double garage; ES, equipment shed; G, garage; GR, granary; H, house; HH, hog house; KK, corn crib; LT, lean-to; OCC, old chicken coop; RH, rabbit house; S, shed; SB, small barn; TS, toolshop.

summers and early autumns for a fouryear period beginning in 1959. Samples were collected from the following six farmsteads which were separated from one another by cultivated fields (Fig. 1):

1) The Mamarrow farm-located on Textile Road about 0.4 miles west of the Ann ArborSaline Road. Mice were caught in seven of the ten buildings on this farm, over a four-year period.

2) Textile Road Barn-an isolated building standing about 0.15 miles west of the Mamarrow farm and isolated from all other buildings by cultivated fields. The barn was used as storage for grain and hay. Only two collections (1961 and 1962) were made in this building.

3) The Guenther farm-located 0.1 miles west of the Textile Road Barn. Of the seven buildings in this complex only two, the barn and the corn crib, yielded mice over a three-year period.

4) The O. Lindeman farm-situated 0.5 miles west of the Guenther farm. During a three-year period, trapping in only two of the four major buildings (corn crib and barn) resulted in catches.

5) The G. Lindeman farm-on Zeeb Road 0.4 miles northwest of the $O$. Lindeman farm. Of the eight major buildings on this farm mice were cap- tured in six, in the course of four annual collections.

6) The Gibbs farm-located on Elisworth Road about 0.6 miles east of Carpenter Road. Only one collection (1962) was made in this area.

The first five collecting areas are located about 6 miles southwest of Ann Arbor, Michigan, and the sixth is located about 5 miles to the southeast of this city. The two areas are approximately 8 miles apart.

Live traps were set in buildings by arranging them at more or less regular intervals along walls and on ledges wherever there were any signs of mice, and where they would not be disturbed by people.

\section{Genetics of the Biochemical VARIANTS STUdied}

1) Prealbumin serum esterase component.-The serum esterases of the house mouse can be subdivided into at least eleven electrophoretically distinct compo- 
nents using alpha naphthyl butyrate as the substrate. Recently, the inheritance of variations involving the fastest migrating serum esterase has been described (Petras, 1963). The three observed phenotypes: no first band, light first band, and dark first band, are under the control of two alleles, $E s-2^{a}$ (allele resulting in the absence of the first band) and $E s-2^{b}$ (allele resulting in the presence of this band), which lack dominance and are located at a single autosomal locus.

2) Hemoglobins.-Investigation of hemoglobins of several inbred strains of mice by Ranney and Gluecksohn-Waelsch (1955) showed the existence of two electrophoretic patterns. In some strains only one discrete component was observed (single), whereas in others preceding and trailing the major component were a number of minor components (diffuse). From breeding results, Gluecksohn-Waelsch, Ranney and Sisken (1957), and Russell and Gerald (1958) concluded that these two patterns were inherited as if controlled by a pair of alleles $\left(H b^{8}\right.$ and $\left.H b^{d}\right)$ at a single autosomal locus $(H b)$. These conclusions were confirmed by Popp and St. Amand (1960) using starch-gel zone electrophoresis. The latter method also permitted distinction between homozygous and heterozygous diffuse genotypes (Shreffler, personal communication). Recently, a more critical examination of mouse hemoglobins, involving a combination of "fingerprinting," chain separation, and isolation of hemoglobin by column chromatography, revealed the existence of two different $\beta$-chains in diffuse hemoglobin and only one type of $\beta$-chain in single hemoglobin (Hutton, Bishop, Schweet and Russell, 1962).

3) Albumin-associated serum esterases.Popp and Popp (1962) described two electrophoretic patterns in the serum albumin region of inbred strains of mice. Several strains have a single band of esterase activity in this region and the rest have two bands of slower mobility. Breeding data suggest that these two types are under the control of two codominant alleles at a sin- gle autosomal locus (Es-1). The heterozygote can be recognized by the appearance of three bands in the albumin region. 4) Transferrins.--Shreffler (1960), using starch-gel electrophoresis in the screening of the sera of a number of inbred strains of Mus musculus, found two distinct transferrin patterns. All but one of the inbred strains examined presented an identical transferrin picture. In the exception, CBA, the transferrin component migrated somewhat faster than in the rest. This component has been designated $\operatorname{Trf}-1$ and the slower type $\operatorname{Trf}-2$. The heterozygote produced by mating $\operatorname{Trf}-1$ and $\operatorname{Tr} f-2$ animals possessed both components. Cohen (1960) and Ashton and Braden (1961) found a similar situation in their electrophoretic studies of these serum proteins in inbred mouse strains. In all cases the results were consistent with the hypothesis that the transferrins are primarily under the control of a pair of codominant alleles at a single autosomal locus.

\section{MethoD}

A sample of blood was obtained from the suborbital canthal sinus of the donor mouse by means of a $1.5-2.0 \mathrm{~mm}$ capillary tube. Approximately $0.5 \mathrm{cc}$ of blood was readily obtained without noticeably harming the mouse.

For the serum esterases and transferrins, the sample was centrifuged at room temperature immediately after being collected, and was stored overnight at $4 \mathrm{C}$. Blood for hemoglobin typing was placed in $1.0 \mathrm{cc}$ of $4 \%$ sodium citrate solution immediately after bleeding. Following the separation of cells from the serum and sodium citrate by centrifugation, the erythrocytes were washed three times in buffered saline, and then lysed by shaking for 10 minutes with equal volumes of distilled water and toluene. The toluene facilitated the separation of the cell ghosts from the hemoglobin.

For electrophoresis approximately 10 lambda of serum were placed on a $5 \times 10$ mm strip of Whatman No. 1 filter paper and a $4 \times 5 \mathrm{~mm}$ strip of the same type 
TABLE 1. Distribution of phenotypes of Prealbumin Serum Esterase and estimated allelic frequencies with their standard errors (s), in feral populations of Mus musculus.

\begin{tabular}{|c|c|c|c|c|c|c|c|}
\hline \multirow[b]{2}{*}{ Locality } & \multirow[b]{2}{*}{ Year } & \multirow[b]{2}{*}{$n$} & \multicolumn{3}{|c|}{ Phenotypes } & \multirow{2}{*}{$\begin{array}{c}\text { Freq. } E_{s-2^{a}} \\
p \pm s\end{array}$} & \multirow{2}{*}{$\begin{array}{c}\text { Freq. } E s-2^{b} \\
q \pm s\end{array}$} \\
\hline & & & Absent & Light & Dark & & \\
\hline \multirow[t]{4}{*}{ Mamarrow } & 1960 & 14 & 2 & 3 & 9 & 0.25 & 0.75 \\
\hline & 1961 & 36 & 2 & 17 & 17 & 0.29 & 0.71 \\
\hline & 1962 & 26 & 4 & 10 & 12 & 0.35 & 0.65 \\
\hline & Pooled & 76 & 8 & 30 & 38 & $0.303 \pm 0.037$ & $0.697 \pm 0.037$ \\
\hline \multirow{4}{*}{ G. Lindeman } & 1960 & 5 & 0 & 1 & 4 & 0.10 & 0.90 \\
\hline & 1961 & 30 & 1 & 8 & 21 & 0.17 & 0.83 \\
\hline & 1962 & 74 & 11 & 26 & 37 & 0.32 & 0.68 \\
\hline & Pooled & 109 & 12 & 35 & 62 & $0.271 \pm 0.030$ & $0.729 \pm 0.030$ \\
\hline \multirow[t]{4}{*}{ O. Lindeman } & 1960 & 4 & 0 & 2 & 2 & 0.25 & 0.75 \\
\hline & 1961 & 17 & 1 & 7 & 9 & 0.26 & 0.74 \\
\hline & 1962 & 19 & 4 & 8 & 7 & 0.42 & 0.58 \\
\hline & Pooled & 40 & 5 & 17 & 18 & $0.337 \pm 0.053$ & $0.663 \pm 0.053$ \\
\hline \multirow[t]{4}{*}{ Guenther } & 1960 & 6 & 1 & 2 & 3 & 0.33 & 0.67 \\
\hline & 1961 & 5 & 1 & 2 & 2 & 0.30 & 0.70 \\
\hline & 1962 & 13 & 2 & 4 & 7 & 0.31 & 0.69 \\
\hline & Pooled & 24 & 4 & 8 & 12 & $0.333 \pm 0.068$ & $0.667 \pm 0.068$ \\
\hline \multirow{3}{*}{$\begin{array}{l}\text { Textile Road } \\
\text { Barn }\end{array}$} & 1961 & 14 & 3 & 3 & 8 & 0.32 & 0.68 \\
\hline & 1962 & 12 & 4 & 4 & 4 & 0.50 & 0.50 \\
\hline & Pooled & 26 & 7 & 7 & 12 & $0.404 \pm 0.068$ & $0.596 \pm 0.068$ \\
\hline Gibbs & 1962 & 21 & 2 & 5 & 14 & $0.214 \pm 0.063$ & $0.786 \pm 0.063$ \\
\hline POOLED & & 296 & 38 & 102 & 156 & $0.301 \pm 0.019$ & $0.699 \pm 0.019$ \\
\hline
\end{tabular}

of filter paper was saturated with the hemoglobin solution. The strips were then inserted into slits in $120 \times 45 \mathrm{~mm}$ starchgel slabs. Connaught Laboratories (Toronto, Ontario) hydrolized potato starch was used for the gels. A gradient of $6 \mathrm{v} / \mathrm{cm}$ was maintained along the horizontally placed starch-gel for 5 and 6 hours for serum proteins and hemoglobins, respectively, at room temperature. The bridge and gel buffers were, respectively, 0.3 and 0.03 molar borate (boric acid and sodium metaborate), with a $p H$ in each case of about 8.5. Other details of the electrophoretic procedure are similar to those reported by Markert and Hunter (1959).

After electrophoresis all starch-gel slabs were sliced horizontally into upper and lower halves to expose the more distinct patterns in the center. One of the halves supporting the serum proteins was incubated for 30 minutes at $37 \mathrm{C}$ in alpha naphthyl butyrate diazonium mixture (see Petras, 1963 for composition) and the other half was placed in a saturated solution of Amido Black 10B for 15 minutes to bring out the transferrin patterns. The Amido Black 10B is dissolved in a solution of 1 part acetic acid, 5 parts methanol and 5 parts water. Excess Amido Black 10B was removed by destaining with this solvent.

The Amido Black 10B procedure was also used for staining one-half of the hemoglobin-carrying starch-gel. With this procedure three distinct hemoglobin types have been observed in Mus musculus: (1) single type-only one relatively narrow, prominent band is observed (presumably homozygous for the allele $H b^{8}$ ); (2) diffuse type with a distinct trailing band; and (3) diffuse type without a distinct trailing band. A study of inbred strains $\mathrm{C} 57 \mathrm{Bl} / 6$ (single $H b^{8} / H b^{8}$ ) and $\mathrm{C} 3 \mathrm{H}$ (dif- 
TABlE 2. A comparison of the numbers of observed phenotypes of Prealbumin Serum Esterase, with those expected as a result of a Hardy-Weinberg Equilibrium.

\begin{tabular}{|c|c|c|c|c|c|c|c|c|c|c|}
\hline \multirow[b]{2}{*}{ Locality } & \multirow[b]{2}{*}{$n$} & \multicolumn{2}{|c|}{$E s-2^{b} / E s-2^{b}$} & \multicolumn{2}{|c|}{$E s-2^{a} / E s-2^{b}$} & \multicolumn{2}{|c|}{$E s-2^{a} / E_{s-2^{a}}$} & \multirow[b]{2}{*}{$x^{2}$} & \multirow[b]{2}{*}{ DP } & \multirow[b]{2}{*}{$P$} \\
\hline & & $\begin{array}{c}\text { Ob- } \\
\text { served }\end{array}$ & $\underset{\left(n p^{2}\right)}{\text { Expected }}$ & $\begin{array}{c}\text { Ob- } \\
\text { served }\end{array}$ & $\underset{(2 n p q)}{\text { Expected }}$ & $\begin{array}{c}\text { Ob. } \\
\text { served }\end{array}$ & $\begin{array}{c}\text { Expected } \\
\left(n q^{2}\right)\end{array}$ & & & \\
\hline Mamarrow & 76 & 38 & 36.96 & 30 & 32.08 & 8 & 6.96 & 0.32 & 1 & $>.50$ \\
\hline G. Lindeman & 109 & 62 & 57.98 & 35 & 43.03 & 12 & 7.98 & 3.80 & 1 & $>.05$ \\
\hline O. Lindeman & 40 & 18 & 17.56 & 17 & 17.89 & 5 & 4.56 & 0.10 & 1 & $>.75$ \\
\hline Guenther & 24 & 12 & 10.67 & 8 & 10.67 & 4 & 2.67 & 1.50 & 1 & $>.10$ \\
\hline Textile Road Barn & 26 & 12 & 9.24 & 7 & 12.52 & 7 & 4.24 & 5.05 & 1 & $<.03$ \\
\hline Gibbs & 21 & 14 & 12.96 & 5 & 7.07 & 2 & 0.96 & 1.80 & 1 & $>.10$ \\
\hline Sum of $\chi^{2}$ 's & & & & & & & & 12.57 & 6 & $>.05$ \\
\hline POOLED $\chi^{2}$ & 296 & 156 & 144.76 & 102 & 124.48 & 38 & 26.76 & 9.65 & 1 & $<.005$ \\
\hline Heterogeneity $\chi^{2}$ & & & & & & & & 2.92 & 5 & $>.50$ \\
\hline
\end{tabular}

fuse $\left.H b^{d} / H b^{d}\right)$ and hybrid $\mathrm{C} 57 \mathrm{Bl} / 6 \times$ $\mathrm{C} 3 \mathrm{H}$ (diffuse $H b^{d} / H b^{8}$ ) has revealed that a distinct band along the posterior edge of the tail, trailing the prominent band, is found only in homozygotes $\left(H b^{d} / H b^{d}\right)$. In heterozygotes $\left(H b^{d} / H b^{8}\right)$ the trailing edge fades out gradually.

\section{Population Data for the $E s-2$ Locus}

The frequencies of the two alleles ( $E s-2^{a}$ and $E s-2^{b}$ ) controlling the phenotypes of the fastest migrating serum esterase component were estimated directly from the frequencies of the zygotic types by maximum likelihood estimates (Cotterman, 1954). These, together with their standard errors, are listed in Table 1. The standard errors were calculated assuming random mating (Cotterman, 1954) and as a result are minimal estimates, because with any structuring of the population the variance is increased (Kempthorne, 1957, Chapter 2; Rasmussen, 1964, appendix).

The standard errors of the allelic frequencies indicate that they do not differ significantly among localities. This conclusion was also substantiated by comparing the allelic frequencies of the various samples using the following test of homogeneity (Neel and Schull, 1954: 204)

and

$$
x^{2}=\frac{\Sigma p X-\bar{p} \Sigma X}{\overline{p q}}
$$

$$
\text { d.f. }=k-1 \text {, }
$$

where $p$ is the frequency of one of the alleles; $\bar{p}$ and $\bar{q}$ are the pooled frequencies of the two alleles; $X$ is the numerical count of the allele which appears with the frequency $p$; and $k$ is the number of samples being compared $\left(\chi^{2}=14.51 ; d . f .=14 ; P>.50\right)$.

These results are consistent with the hypothesis that the two alleles at this locus form a stable polymorphism which is probably maintained by a maximum intralocus fitness of the heterozygote $(\mathrm{Li}, 1955 a)$.

Similarly, the differences in the observed phenotypic frequencies (Table 1 ) that exist between localities and years are not statistically significant. The contingency chisquares for homogeneity are as follows: six localities $\times$ three phenotypes, $\chi^{2}=9.62$, d.f. $=10, P>.25$; three years $\times$ three phenotypes, $\chi^{2}=5.30$, d.f. $=4, P>.25$. A similar conclusion can be drawn from the heterogeneity $\chi^{2}$ seen in Table 2 . An examination of the distribution of the three phenotypes in the two sexes also revealed no significant deviation $\left(\chi^{2}=2.55\right.$, d.f. $=$ 2, $P>.25$ ).

From the allelic frequencies, the frequencies of the three $E s-2$ phenotypes expected under a Hardy-Weinberg equilibrium were calculated. In all six samples (see Table 2), a numerical deficiency of heterozygotes was observed. In the individual samples from four localities the differences between observed and expected genotypic frequencies were not statistically sig- 
TABLE 3. Distribution of Hemoglobin phenotypes and estimated allelic frequencies with their standard errors (s) in feral populations of Mus musculus.

\begin{tabular}{|c|c|c|c|c|c|c|c|}
\hline \multirow[b]{2}{*}{ Locality } & \multirow[b]{2}{*}{ Year } & \multirow[b]{2}{*}{$n$} & \multicolumn{3}{|c|}{ Phenotypes } & \multirow[b]{2}{*}{$\underset{p=s}{\text { Freq. } H b^{d}}$} & \multirow[b]{2}{*}{$\begin{array}{c}\text { Freq. } H b^{s} \\
q \pm s\end{array}$} \\
\hline & & & $\begin{array}{c}\text { Diffuse } \\
\text { with trail- } \\
\text { ing band }\end{array}$ & $\begin{array}{c}\text { Diffuse } \\
\text { with no } \\
\text { trailing } \\
\text { band } \\
\end{array}$ & Single & & \\
\hline \multirow[t]{4}{*}{ Mamarrow } & 1960 & 18 & 2 & 8 & 8 & 0.33 & 0.67 \\
\hline & 1961 & 36 & 2 & 10 & 24 & 0.19 & 0.81 \\
\hline & 1962 & 22 & 1 & 9 & 12 & 0.25 & 0.75 \\
\hline & Pooled & 76 & 5 & 27 & 44 & $0.243 \pm 0.035$ & $0.757 \pm 0.035$ \\
\hline \multirow[t]{4}{*}{ G. Lindeman } & 1960 & 15 & 1 & 5 & 9 & 0.23 & 0.77 \\
\hline & 1961 & 30 & 2 & 13 & 15 & 0.28 & 0.72 \\
\hline & 1962 & 60 & 15 & 28 & 17 & 0.48 & 0.52 \\
\hline & Pooled & 105 & 18 & 46 & 41 & $0.390 \pm 0.034$ & $0.610 \pm 0.034$ \\
\hline \multirow[t]{4}{*}{ O. Lindeman } & 1960 & 8 & 0 & 4 & 4 & 0.25 & 0.75 \\
\hline & 1961 & 21 & 3 & 5 & 13 & 0.26 & 0.74 \\
\hline & 1962 & 17 & 3 & 7 & 7 & 0.38 & 0.62 \\
\hline & Pooled & 46 & 6 & 16 & 24 & $0.304 \pm 0.048$ & $0.696 \pm 0.048$ \\
\hline \multirow[t]{4}{*}{ Guenther } & 1960 & 5 & 1 & 1 & 3 & 0.30 & 0.70 \\
\hline & 1961 & 5 & 1 & 1 & 3 & 0.30 & 0.70 \\
\hline & 1962 & 13 & 2 & 5 & 6 & 0.35 & 0.65 \\
\hline & Pooled & 23 & 4 & 7 & 12 & $0.326 \pm 0.069$ & $0.674 \pm 0.069$ \\
\hline \multirow{3}{*}{$\begin{array}{l}\text { Textile Road } \\
\text { Barn }\end{array}$} & 1961 & 13 & 0 & 4 & 9 & 0.15 & 0.85 \\
\hline & 1962 & 10 & 0 & 1 & 9 & 0.05 & 0.95 \\
\hline & Pooled & 23 & 0 & 5 & 18 & $0.109 \pm 0.046$ & $0.891 \pm 0.046$ \\
\hline POOLED & & 273 & 33 & 101 & 139 & $0.306 \pm 0.020$ & $0.694 \pm 0.020$ \\
\hline
\end{tabular}

nificant $(P>.10)$, and for the fifth sample the chi-square was $5.05(P<.03)$. However, in the pooled data the deviations from expected gave a highly significant chisquare $(P<.005)$.

\section{Population Data for the $H b$ Locus}

The maximum likelihood procedure was also used to estimate directly the frequencies of the two alleles at the hemoglobin locus. These frequencies together with their standard errors are summarized in Table 3. The latter, because they are based on panmixia, are once again minimal estimates.

The standard errors suggest that pooled samples from some localities differ from the rest. A test of homogeneity (see above) revealed heterogeneity in the gene frequencies of the 14 samples $\left(\chi^{2}=32.39\right.$, d.f. $=$ 13 and $P<.005)$. The greatest contribution to this heterogeneity came from the $G$.
Lindeman 1962 sample. When this sample was not included in the test of homogeneity no significant variations were found $\left(\chi^{2}=\right.$ 11.76, d.f. $=12$ and $P>.50$ ).

An examination of the phenotypic frequencies reveals a similar situation. Contingency chi-squares for homogeneity are (1) five localities (annual samples pooled) $X$ three phenotypes, $x^{2}=17.65, d . f .=8$, $P<.025$; (2) three years $\times$ three phenotypes, $x^{2}=10.37$, d.f. $=4, P<.05$.

In the former test, the $G$. Lindeman sample and in the latter the 1962 sample were the greatest contributors to the heterogeneity chi-square. To focus more sharply on the source of heterogeneity the two contingency tests for homogeneity were rerun but without the G. Lindeman 1962 sample. Both, the five localities $X$ three phenotypes and three years $x$ three phenotypes contingency tests, revealed no heterogeneity $\left(\chi^{2}=9.58\right.$, d.f. $=8, P>.25 ; \chi^{2}=1.31$, d.f. $=4, P>.75)$. 
TABLE 4. A comparison of the number of Hemoglobin phenotypes observed, with those expected as a result of a Hardy-Weinberg Equilibrium $(\mathbf{F}=0)$ and those expected when the coefficient of inbreeding (F) is 0.18 .

\begin{tabular}{|c|c|c|c|c|c|c|c|c|c|c|c|c|c|}
\hline \multirow[b]{3}{*}{ Locality } & \multirow[b]{3}{*}{$n$} & \multicolumn{3}{|c|}{$H b^{d} / H b^{d}$} & \multicolumn{3}{|c|}{$H b^{d} / H b^{d}$} & \multicolumn{3}{|c|}{$H b^{s} / H b^{s}$} & \\
\hline & & \multicolumn{3}{|c|}{ Expected } & \multicolumn{3}{|c|}{ Expected } & \multicolumn{3}{|c|}{ Expected } & & & \\
\hline & & Obs. & $F=0$ & $F=0.18$ & Obs. & $F=0$ & $F=0.18$ & Obs. & $F=0$ & $F=0.18$ & \multicolumn{3}{|c|}{$x^{2}$} \\
\hline Mamarrow & 76 & 5 & 4.50 & 7.02 & 27 & 27.99 & 22.96 & 44 & 43.50 & 46.20 & $\begin{array}{l}0.10 \\
P>.75\end{array}$ & $\begin{array}{l}1.38 \\
P>.50\end{array}$ & 1 \\
\hline G. Lindeman & 105 & 18 & 16.01 & 20.51 & 46 & 49.98 & 40.99 & 41 & 39.01 & 43.51 & $\begin{array}{l}0.67 \\
P>.25\end{array}$ & $\begin{array}{l}1.06 \\
P>.75\end{array}$ & 1 \\
\hline o. Lindeman & 46 & 6 & 4.26 & 6.01 & 16 & 19.48 & 15.98 & 24 & 22.26 & 24.01 & $\begin{array}{l}1.47 \\
P>.10\end{array}$ & $\begin{array}{l}0.00 \\
P>.99\end{array}$ & 1 \\
\hline Guenther & 23 & 4 & 2.45 & 3.36 & 7 & 10.11 & 8.29 & 12 & 10.45 & 11.36 & $\begin{array}{l}2.18 \\
P>.10\end{array}$ & $\begin{array}{l}0.36 \\
P>.50\end{array}$ & 1 \\
\hline $\begin{array}{l}\text { Textile Road } \\
\text { Barn }\end{array}$ & 23 & 0 & 0.27 & 0.67 & 5 & 4.46 & 3.65 & 18 & 18.27 & 18.67 & $\begin{array}{l}0.24 \\
P>.50\end{array}$ & $\begin{array}{l}1.20 \\
P>.25\end{array}$ & 1 \\
\hline SuM of $\chi^{2}$ 's & & & & & & & & & & & $\begin{array}{l}4.65 \\
P>.25\end{array}$ & $\begin{array}{l}4.00 \\
P>.25\end{array}$ & 5 \\
\hline POOLED $\chi^{2}$ & 273 & 33 & 25.54 & 35.99 & 101 & 115.92 & 95.05 & 139 & 131.54 & 141.97 & $\begin{array}{l}4.52 \\
P<.05\end{array}$ & $\begin{array}{l}0.68 \\
P>.25\end{array}$ & 1 \\
\hline Heterogeneit & $y x^{2}$ & & & & & & & & & & $\begin{array}{l}0.13 \\
P>.90\end{array}$ & $\begin{array}{l}3.32 \\
P>.50\end{array}$ & 4 \\
\hline
\end{tabular}

The present data are inadequate to explain the frequency heterogeneity observed in the samples. Since these differences do exist no conclusions can be drawn about the stability of the $H b$ polymorphism. Nevertheless, a polymorphism does exist, and, as is seen in Table 4, once again the number of heterozygotes observed is lower than the number expected under a HardyWeinberg equilibrium. This deficiency is significant at the 5\% level. Also, once again the overall deficiency is a reflection of consistent, statistically nonsignificant deficiencies in nearly all the populations. The one exception is a small sample from the Textile Road Barn.

\section{Population Data for the Remaining BIOCHEMICAL VARIANTS}

The Ann Arbor samples showed no polymorphism at the other two loci examined. At the Es-1 locus all animals appear to be genotype $E s-1^{b} / E s-1^{b} . E s-1^{b}$ is the allele for two slow-moving albumin-associated esterase bands. No $E s-1^{a} / E s-1^{a}$ mice were found. It is conceivable that in the earlier phases of this study some $E s-1^{a} / E s-1^{b}$ ani- mals might have been misclassified as $E s$ $1^{b} / E s-1^{b}$. However, there is no evidence to suggest this except that these two genotypes are rather difficult to distinguish phenotypically.

The mice in the populations sampled appear to be homozygous for the Trf-2 allele at the transferrin locus.

\section{Possible Explanations for \\ Deficiencies of Heterozygotes}

Discrepancies between heterozygotes observed and the number expected under random mating can be explained in a number of ways. These include:

1) selection against the heterozygotes and thus an elimination of these;

2) positive phenotypic assortative mating;

3) subdivision of the total population into small breeding units and associated correlation of gametes.

Selection would appear to be a most unlikely cause for the shortage of heterozygotes in a stable polymorphism such as appears to be the situation at the $E s-2$ 
locus. As pointed out by Rasmussen (1962) "if the shortage of heterozygotes is due to the relative intralocus selective disadvantage of the heterozygous type, the polymorphic system would be an unstable one and the homogeneity between samples would imply that all samples were taken in the same stage of change toward a maximal intralocus fitness at which $p$ or $q$ approaches zero" (see also Li, 1955a). Therefore, homogeneity of samples collected from a number of different localities, in different years, makes a selective disadvantage of the heterozygote the cause of the numerical deficiency of heterozygotes very unlikely.

Also the possibility of phenotypic assortative mating, when the phenotype does not appear to be expressed externally, seems very remote.

Assuming a two-allele system, there is one other simple explanation for a numerical deficiency of heterozygotes at such a locus as the Es-2, which would also, simultaneously, explain a similar deficiency at the $H b$ locus. This is population structuring, that is the subdivision of a population into a number of small, more or less isolated breeding units.

A comparison of pooled zygotic frequencies of the isolates with those expected if the larger population were not subdivided but instead panmictic, reveals a higher proportion of homozygotes (by the amount $\sigma_{q}{ }^{2}$, where $q$ is the frequency of one of the alleles) in the former than would be expected if there were no subdivision. This increase in homozygotes at the expense of the heterozygotes is referred to as the Wahlund effect by Li (1955b: 298).

Since "subdivision of a population into separate breeding groups is equivalent to the practice of inbreeding within the whole population" ( $\mathrm{Li}, 1955 b)$, an inbreeding coefficient $(F)$ can be calculated from the numerical deficiency of heterozygotes in the entire population. $\mathrm{Li}$ and Horvitz (1953) describe various estimates of the gametic correlation utilizing the observed proportion of zygotic types. One such estimate is obtained by: $f=\left(H_{e}-H_{o}\right) / H_{e}$, where $H_{e}$ is the frequency of heterozygotes expected on the basis of a Hardy-Weinberg equilibrium, $H_{e}=2 p q$, and $H_{o}$ is the proportion of heterozygotes observed. This is the maximum likelihood estimate of the inbreeding coefficient when $p+q=1$. Estimates of $F$ based on the $E s-2$ data and their standard errors calculated according to Rasmussen (1964, appendix) are given in Table 5 . In the small samples the estimates of $F$ do not differ significantly from panmixia $(F=0)$. This of course does not mean that these populations are panmictic but only that if deviations from panmixia exist they cannot be detected because of sample size. For the pooled sample the estimate of $F$ from $E s-2$ locus is $0.18 \pm .063$.

If an inbreeding coefficient of 0.18 is assumed, the fit of the hemoglobin data is better $\left(\chi^{2}=0.68\right.$, d.f. $\left.=1, P>.25\right)$ than it is in the panmictic model. If the inbreeding coefficient is calculated directly from the hemoglobin data, the estimate of $F$ is $0.13 \pm .062$.

The good fit of both the Es-2 and the $H b$ data to a population model with inbreeding coefficient incorporated, supports the idea of population subdivision in the mouse populations sampled.

\section{INBREEDING COEFFICIENT AND BREEDING UNITS}

The existence of an inbreeding coefficient greater than zero and therefore the absence of panmixia, or the existence of population structuring, in the Mus populations sampled is not surprising. As a matter of fact this should be expected in populations of all small mammals, and most bisexual species, since they are generally composed of individuals whose parents have limited dispersal. Therefore, random mating, frequently described as the "simplest mating system" and the basis for population genetics, does not hold true except perhaps in very small populations, or in species in which the individuals demonstrate dispersal of considerable distance between young and adult stages. 
TABLE 5. Estimates of the inbreeding coefficient (f) and the standard errors (s) based on data of the Es-2 locus, from a number of samples of natural populations of the house mouse.

\begin{tabular}{lrrr}
\hline & $n$ & $f$ & $s$ \\
\hline LOCALITY: & & & \\
$\quad$ Mamarrow & 76 & 0.065 & \pm 0.117 \\
G. Lindeman & 109 & 0.187 & \pm 0.101 \\
$\quad \begin{array}{l}\text { O. Lindeman } \\
\text { Guenther }\end{array}$ & 40 & 0.050 & \pm 0.160 \\
$\quad$ Textile Road & 24 & 0.250 & \pm 0.206 \\
$\quad$ Barn & 26 & 0.441 & \pm 0.179 \\
$\quad$ Gibbs & 21 & 0.293 & \pm 0.245 \\
YEAR (Localities & & & \\
Pooled): & & & \\
$\quad$ 1960 & 29 & 0.247 & \pm 0.195 \\
1961 & 102 & 0.057 & \pm 0.102 \\
1962 & 165 & 0.226 & \pm 0.079 \\
\hline POOLED (Localities & & & \\
and Years) & 296 & 0.1804 & \pm 0.0626 \\
\hline
\end{tabular}

In spite of the fact that the main theoretical consequences of mating systems other than random have been extensively discussed by Wright (1921), and the importance to the evolutionary process of such characteristics of populations as finite size, isolation by distance, and reticulate breeding structure, has since been emphasized by many authors (see for example: Wright, 1951; Bartlett and Haldane, 1935; Fisher, 1958), little empirical information is known about these features in natural populations, especially of small mammals.

By combining the coefficient of inbreeding, which can be estimated from empirical studies of stable polymorphisms, with such ecologic data as estimates of migration, an indirect approach can be employed to obtain some estimate of the genetically effective size of randomly breeding units (demes, neighborhoods or panmictic units). For instance, the samples of Mus from the Ann Arbor area revealed an $F>0$, which suggests that these samples came from a number of small panmictic units and not from one large unit.

Wright (1943) showed the interrelationships of the coefficient of inbreeding $(F)$, the size of the randomly breeding unit (ef- fective population size, $N$ ) and the degree of isolation of each panmictic unit $(m)$. Since there are two major types of isolating systems, and since the relationship of $F$, $N$ and $m$ differs from one isolating system to the next, two models are required to describe the extremes. I-Isolation by Distance Model-in which the randomness of gene exchange is limited by the dispersal distance from birth to mating of an individual. This model invokes no physical fragmentation of the population into subgroups. The limits of a randomly mating unit (deme) are determined by the average dispersal distance of the individuals under a set of existing conditions such as density and availability of suitable habitat. II-Island Model-in which a species is divided into a large number of small randomly breeding units. These demes are almost completely isolated from one another by distinct barriers.

If uniform dispersion of individuals and uniform density is assumed over a continuous area (Isolation by Distance Model) Wright's formula (1951):

$$
F=1-\left[1-(1-m)^{2}\right]^{1 / x}
$$

gives a maximum estimate of the inbreeding coefficient $(F) . N$ represents the effective population size and $m$ represents the amount of new or extra-demic genetic material introduced into a deme. There are two sources of this extra-demic material, migration and mutation, with the former probably being by far the more important in natural populations.

The relationship of $F, m$ and $N$ in the Island Model is given by Wright's formula (1951):

$$
F=(1-m)^{2} /\left[2 N-(2 N-1)(1-m)^{2}\right] .
$$

If the extreme is considered, that is where a finite population is completely isolated $(m=0)$, then $F$ will approach one.

If the value $F=0.18$ is assumed (this is minimum $F$ estimate obtained from $E s-2$ population data because of probable selective advantage of the heterozygote) and $m$ falls between 0.02 and 0.20 (the evidence 


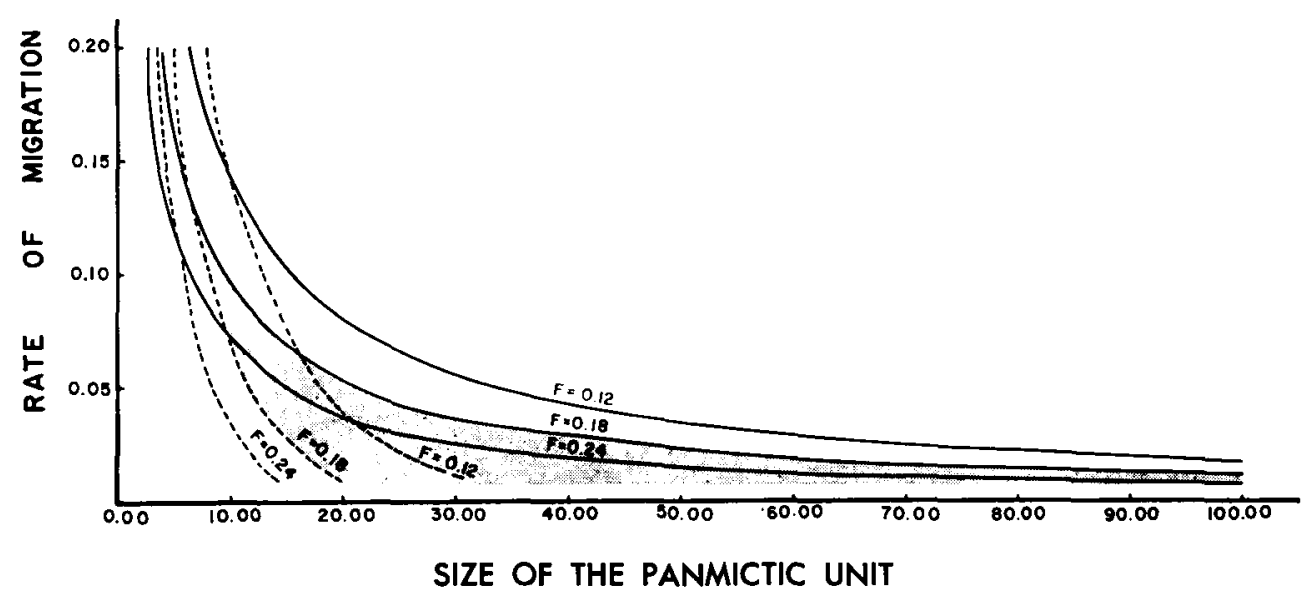

FIG. 2. The relationship that exists between the size of a panmictic unit, the rate of gene exchange between such units (migration) and several inbreeding coefficients, when two extreme population models are considered: (a) Isolation by Distance Model (broken lines) and (b) Island Model (solid lines). The shaded area represents the relationship between the rate of migration and the size of the panmictic unit, when the structuring falls between the two extremes and $F=0.18$, the estimate obtained from the $E s-2$ data.

for these values of $m$ will be discussed later) then the size of the panmictic unit should vary between 6 and 80 if Wright's Island Model obtains, and between 8 and 20 if isolation by distance plays an important role. If the inbreeding coefficient is greater, the size of the panmictic unit decreases, and the reverse occurs when the inbreeding coefficient is smaller. The relationship of $F, m$ and $N$ is seen in Figure 2 .

\section{ECOLOGIC EVIDENCE FOR POPULATION STRUCTURING}

Ecologic studies are in agreement with the conclusions about population structuring drawn from the genetic data. Considerable evidence is available for the three levels of structuring recognized by cursory examination of the general situation in the Ann Arbor region.

a) Structuring within a building.-A number of studies have revealed restricted movement of mice within a building (Young, Strecker and Emlen, 1950; Brown, 1953; Petrusewicz and Andrzejewski, 1962; and Southern and Laurie, 1946). For instance, Young et al. (1950) in a study of two indoor populations in a room 170 feet by 100 feet found house mice to be rather localized in their activity. The average distance moved was 12 feet, with $70 \%$ of the mice moving less than 10 feet and $90 \%$ less than 30 feet. The greatest movement that they recorded was 140 feet. Similarly, limited movement was observed in corn ricks in England. Southern and Laurie (1946) estimated the home range of the house mouse to be about 50 square feet on a single level with very little vertical movement.

A population of mice in a single building may also be fragmented into breeding units as a consequence of social behavior which results in the establishment of definite territories (Crowcroft and Rowe, 1963; Anderson and Hill, 1965; Reimer, J., 1965 [Population structuring in natural populations of the house mouse, Mus musculus $\mathrm{L}$. M.S. Dissertation, Univ. Windsor, Windsor, Ontario.]).

b) Movement of house mice in and out of buildings.-Limited observations in the Ann Arbor region revealed that only two of 12 recaptured mice (17\%) were caught in a building adjacent to the one of their initial capture.

Evans (1949) in studying a house mouse 
population explosion in California found that of 235 mice which occupied or passed through a single ( 42 feet $\times 21$ feet) room long enough to be caught, only four records of movements from indoors to outdoors and vice versa were observed (less than $2 \%$ ). This obviously is an underestimate, because at one time the population in the building appeared to become extinct and the recovery which was observed was probably due to unmarked migrants.

In another similar study Brown (1953) in southeastern United States found no direct evidence for migration between farm and field. He did, however, concede that such movement probably did occur but considered it as having little or no effect on population fluctuations.

Petrusewicz and Andrzejewski (1962) in a two year study of mice in an isolated building found only 21 of 429 individuals $(5 \%)$ moving either into or out of the building.

c) Movement of mice between farm complexes.-Contrary to the findings of a number of investigators [Linduska (1942) in southern Michigan, Justice (1962) in Arizona, and Southern and Laurie (1946) in England] no house mice were captured in cultivated fields over a six-week period of daily trapping during the present study. Justice observed in his study that animals were found only when suitable ground cover was present. The absence of such cover may perhaps explain the results obtained in southeastern Michigan. In spite of dispersal over considerable distances, up to 2000 feet over a continuous habitat, Justice concluded that few, if any, of the mice so dispersed survive and contribute to the gene pool of subsequent generations. The main contribution to these generations comes from a relatively few mice inhabiting undisturbed drainage ditches.

In England, Southern and Laurie (1946) found much the same situation. The mice in fields were not very abundant (128 in 6855 trapnights), and were restricted mainly to cover along hedgerows. These reservoirs supplied immigrants to culti- vated fields and corn ricks after the harvest. This limited supply of newcomers, and the facts that $90 \%$ of the corn ricks which had been standing 9 months supported mouse populations and of these $40 \%$ had less than 50 animals under what might be considered optimal conditions for a population explosion, are a strong indication that only a few mice initially infest a corn rick. Occasionally, because corn ricks provide an excellent habitat for mice the number may increase very quickly, sometimes to as many as 14.0 mice per cubic meter. Therefore, an 80 cubic meter corn rick has been found to support over 1000 animals. However, in spite of this high density, very few mice were observed leaving a corn rick until the threshing was started. Most of the animals released at threshing are preyed upon and, Southern and Laurie concluded, probably do not contribute a significant part to the next generation.

Ecological studies of the house mouse lead to the following generalizations.

1) Mice, because of restricted home range within a building and social behavior, are grouped into small random-mating units or demes. (Isolation by distance).

2) The migration of mice in and out of buildings is rather restricted. The best estimate of physical migration is $5 \%$. If this estimate is valid then the maximum genetically effective migration is no more than $5 \%$, and probably considerably less. (Wright's Island Model).

3) Populations separated by land having no ground cover have a highly restricted exchange of genes. This is especially true if the populations are separated by a considerable distance as is the case between farms. Interfarm migration is therefore, probably negligible. (Wright's Island Model).

\section{ESTIMATES OF EFFECTIVE SIZE OF BREEDING POPULATIONS FROM ECOLOGIC DATA}

The ecologic data collected in the present study are not suitable for the estima- 
tion of genetically effective population size $\left(N_{e}\right)$. However, the data of Rowe, Taylor and Chudley (1963) on the numbers and movements of house mice in the vicinity of four corn ricks in England, can provide such estimates.

The study of Rowe et al. involved the placing of a barrier having openings with traps at regular intervals, around a number of corn ricks. This permitted the numbering and checking of all mice entering and leaving the corn rick. A final check of all the residents of a corn rick was made at threshing which occurred about 10 months after the ricks were built.

Only two ricks of the four studied are useful in estimating $N_{e}$. In Rick $\mathrm{A}$, of the 46 males and 28 females that entered only 6 males and 14 females were alive and healthy (not bitten) at the threshing collection. During the 10 month period the population in Rick A rose to 707 males and 764 females. Included in these figures are juveniles and adults. Forty-four males and 34 females migrated into Rick $B$. Of these only 4 males and 18 females were healthy at threshing. The population in this rick rose to 662 males and 704 females.

Based on the healthy mice, $N_{e}$ of the founder population was 17 in Rick $A$ and 13 in Rick B $\left(N_{e}=4 N_{0} N_{1} /\left[N_{0}+N_{1}\right]\right.$ where $N_{0}$ and $N_{1}$ are the number of males and females, respectively; $\mathrm{Li}, 1955 b$ : 321). $N_{e}$ of the founder population based on all entering mice was calculated to be 70 for Rick A and 77 for Rick B.

With the upper and lower estimates of $N_{e}$ in the founder population and assuming that the rest of the mice in each corn rick belong to a single generation (an assumption that is in all probability incorrect but that does not alter the magnitude of $N_{e}$ significantly), the genetically effective population size of the entire population $\left(\bar{N}_{e}\right)$ at threshing was calculated. The two generation $\bar{N}_{e}$ was found to be between 34 and 134 and between 26 and 146 for Ricks $A$ and $\mathrm{B}$, respectively $\left(1 / \bar{N}_{e}=1 / 2\left[1 / N_{e 1}+\right.\right.$ $\left.1 / N_{e 2}\right]$ where $\bar{N}_{e}$ is the effective size of the whole population over several generations, $N_{e 1}$ and $N_{e z}$ are effective sizes of the population in each of two generations; $\mathbf{L i}$, 1955b: 323). The upper and lower estimates in both cases are based on the two $\bar{N}_{e}$ estimates of the founder populations.

A further examination of the data suggests that the upper limits of the overall $\bar{N}_{e}$ are overestimates. (1) Rowe et al., found that only $85 \%$ of the adults are fecund. This reduces the upper limit of the $\bar{N}_{\varepsilon}$ estimates to 114 and 124 . (2) In calculating the $N_{e}$ of the founder population, it was assumed that all mice contributed equally to the subsequent generation. This is obviously not so for two reasons: (a) not all of the immigrants entered a rick immediately after it was built (about $10 \%$ entered in the ninth and tenth months), and (b) of those that entered early some in all probability died before they could reproduce. Both of these factors reduce the $N_{e}$ of the founder population and contribute considerably to the reduction of the overall $\bar{N}_{e}$. Another factor which will cause $N_{e}$ to be an overestimate is the formation of several panmictic units within a single corn rick instead of just one as assumed.

Even without considering the $\bar{N}_{e}$ values as overestimates the approximation of effective breeding size from the corn rick ecological data $(13-146)$ is of the same order of magnitude as that obtained from the Michigan genetic data $(6-80)$.

\section{POPULATION STRUCTURING AND CONTRIBUTION TO INBREEDING COEFFICIENT}

Assuming that house mice are divided ecologically into subgroups, the contribution to the inbreeding coefficient by the various levels of this subdivision can be obtained by fractionating $F$ according to Wright (1951):

$$
F_{s t}=\left(F_{i t}-F_{i s}\right)\left(1-F_{i s}\right),
$$

where $F_{i t}$ is the inbreeding coefficient for individuals relative to the total, $F_{i s}$ is the average inbreeding coefficient for individ- 
uals relative to a subgroup, and $F_{s t}$ is the correlation between gametes drawn from the same group relative to the total. The values $F_{i s}$ and $F_{i t}$ are obtained from the ratio of average observed heterozygosis within a group to that expected from internal random mating.

If $F_{i t}$ as determined from the $E s-2$ data is $0.180, F_{t s_{1}}$ the average inbreeding coefficient for individuals relative to the total in a single building is 0.010 , and $F_{i s_{2}}$ the average inbreeding coefficient for individuals relative to the total on one farmstead is 0.176 , then $F_{s_{1} t}$ the correlation between gametes drawn from a sample of a single building relative to the total is 0.172 and $F_{s_{g} t}$ the correlation of random gametes drawn from one farmstead relative to the total is 0.005 .

The main contribution to the inbreeding coefficient, therefore, appears to come primarily from the breaking up of a population into subgroups within a farmstead and not within a building. Generally each building contains a population which approaches panmixia. This holds true to a lesser degree for populations in large buildings. For instance, in buildings such as a large barn or a good-sized corn crib, where ecological data suggest the existence of more than one panmictic unit, the mean inbreeding coefficient was found to be 0.063 .

Population discontinuity observed between farms because of unsuitable habitat, appears to contribute very little to the inbreeding coefficient.

\section{General Concept of a Mus Population AND its Significance}

Both genetic and ecologic data suggest that the commensal house mouse forms small panmictic units or demes which are to a considerable degree isolated from one another as a result of social behavior, interdemic distance, and interspersed unsuitable habitats. In spite of the fact that the effects of farming practices on mouse populations are difficult to evaluate, data obtained from the present study together with information obtained by other investigators are sufficient to provide a general picture of the population structure of these small commensal mammals.

Mouse populations, that are associated with human habitations, may be classified into two general types: relatively permanent populations and transient populations (Brown, 1953; Rowe, Taylor, and Chudley, 1963). The former include those found in buildings in which food and cover are available year round (e.g., barns, chicken coops, etc.) and the latter include the populations restricted to buildings or other areas in which foodstuffs and cover are completely removed or radically disturbed at least once a year (e.g., corn crib or wheat field). Associated with the latter is a substantial annual turnover of mice. There is no sharp distinction between these two types of populations.

With very few exceptions Mus musculus populations demonstrate numerical fluctuations (Brown, 1953; Justice, 1962; Petrusewicz and Andrzejewski, 1962; Southern and Laurie, 1946). Although such factors as changes in the climate and size of predator populations play a role in these fluctuations, the major factors in the Michigan populations studied and perhaps English Mus populations are probably those associated with farm practices. Populations in such buildings as chicken coops, probably show very slight numerical fluctuations because environmental resources remain stable over a considerable period of time (several years). Excess mice, usually young adults, are continuously forced out into adjacent buildings or fields. Those in buildings where the quantity of foodstuffs and cover changes from time to time (e.g., barn) undergo continuous numerical change. Usually, a maximal size is reached in the late winter and early spring while ample food and cover are available (Brown, 1953). The gradual reduction of these commodities and the continued growth of the population result in increased emigration in the spring (Rowe et al., 1963). This causes a reduction in the size of the population, which 
reaches a minimal level just prior to the storage of the new crop. In Michigan, this occurs in midsummer. The emigrants probably enter neighboring fields or buildings where they either become re-established if a vacancy is present, or fall prey to carnivores and birds (Justice, 1962; Petrusewicz and Andrzejewski, 1962).

Transient populations demonstrate more stringent numerical bottlenecks $\left(N_{e}\right.$ is very small) than the permanent ones, and often become extinct, only to be replaced by migrants from permanent populations. In a structure such as the corn crib in southeastern Michigan or the corn rick in England, a population usually reaches its peak in early spring and then decreases in size with the removal of the food supply. In the case of a corn crib the removal of food and cover is gradual, whereas in the English corn rick it is sudden, taking place at the threshing period. In both cases all of the inhabitants are eventually forced into the fields and hedgerows. With the refilling of the storage bins or the building of new corn ricks, immigrants from the fields and perhaps from neighboring buildings form a foundation stock. Data of Rowe et al. (1963) suggest that the genetically effective size of the foundation stock is considerably less than the number that entered, perhaps as low as $10-20$ mice.

Mice found in the fields also form, for the most part, a transient population. Unfortunately, data on the continuity and reproductive potential of such populations are meager. There is evidence that in England at least a few survive the winter in hedgerows (Rowe et al., 1963). Perhaps these field populations serve mainly as reservoirs for excess mice and animals whose original habitat was disturbed, and so their chief value may lie as a possible source of foundation stocks for colonizing newly-formed habitats.

Once a population becomes established in a particular building it is unlikely, because of territoriality and associated social hierarchy, that any effective immigration occurs (Crowcroft and Rowe, 1963; and An- derson, 1964). If the population density is high, an immigrant is either killed or driven off. However, if the population density is low then, perhaps, foreign mice may survive in areas undefended by endemic animals. Nevertheless, even in such cases the "new-comers" and "old-timers" probably remain members of distinct breeding units with only rare gene exchanges taking place between such units (Reimer, loc. cit.). For these reasons, the most suitable conditions for the mixing of genes of two or more demes arise during the formation of a founder stock. Animals from a number of different demes can at this time become simultaneously established in a new habitat. New family groups are formed before immigrant males develop territorial behavior.

The preceding population model fits the genetic data collected in the Ann Arbor region. The estimates of the inbreeding coefficient obtained from studies of the $E s-2$ and $H b$ loci are readily explained by the existence of small random breeding units with limited migration between them, and the frequent occurrences of numerical bottlenecks. The existence of the small demes also provides a suitable explanation for the low empirical frequencies of the $t$-allele (Petras, 1965). This explanation was first proposed by Lewontin and Dunn (1960) on the basis of a computer analogue population and more recently supported by the empirical data of Anderson (1964). Extinction of demes and small founder populations readily give support to genetic drift as the cause of the significant frequency differences of the skeletal variants (Berry, 1964; Petras, 1965). Genetic drift may also be involved in significant erythrocytic antigenic differences in two populations of Mus located in buildings no more than 65 feet apart (Petras, Singer, and Foster, 1964).

These small breeding units are also of general evolutionary value but since this has been discussed eloquently on numerous occasions by Wright (see for example, 
1940), no attempt will be made to reiterate the arguments.

\section{SUMMARY}

1) House mice (Mus musculus) collected from the buildings of six neighboring farms in southeastern Michigan over a four-year period, were examined for the existence of polymorphisms at four loci controlling biochemical variants.

2) Two of the four loci examined, the esterase-2 (Es-2) locus and the hemoglobin $(H b)$ locus, revealed the existence of polymorphisms. The overall frequencies of the less common alleles at these loci are: $0.301 \pm .019$ for the $E s-2^{a}$ allele and $0.306 \pm .020$ for the $H b^{d}$ allele.

3) The samples of Mus musculus when pooled revealed a significant numerical deficiency of heterozygotes at both the Es-2 and $H b$ loci. Analyses revealed that these shortages of heterozygotes at both loci can be explained best by population structuring and the associated gametic correlation. Estimates of inbreeding coefficients obtained from these loci were of the order of $f=$ $0.06-0.30$.

4) Ecologic data suggested three levels of population structuring with restricted migration between units at any level.

5) Wright's population models were used to obtain estimates of the effective size of the panmictic units $\left(N_{e}=6-80\right)$. Estimates of the same magnitude were obtained from ecologic data.

6) Also discussed were the general population structure of commensal rodent populations and the value of the small breeding units in explaining several genetic phenomena observed in mouse populations.

\section{ACKNOWLEDGMENTS}

I am especially grateful to the following members of the faculty of The University of Michigan: Dr. Morris Foster, Department of Zoology, for his continuous and enthusiastic encouragement and his invaluable advice both in research and the preparation of this paper; Dr. W. H. Burt, Department of Zoology, Dr. T. M. Rizki, De- partment of Zoology, and Dr. W. J. Schull, Department of Human Genetics, for their valuable suggestions.

Special thanks are also due to: Miss $\mathrm{Pa}$ tricia Tomlin for her technical assistance and Dr. S. L. Beck, Mr. B. Levin, Dr. D. I. Rasmussen, and Mr. J. D. Reimer for numerous helpful discussions.

I would like to acknowledge support by USPHS Genetics Training Grant (26-71C3, Neel), USPHS Research Grants (CA05559, CA-04305, AM-08167) and a National Research Council of Canada Grant (A-867).

\section{Literature Cited}

Anderson, P. K. 1964. Lethal alleles in Mus musculus: local distribution and evidence for isolation of demes. Science 145: 177-178.

Anderson, P. K., ANd J. L. Hill. 1965. Mus musculus: Experimental induction of territory formation. Science 148: 1753-1755.

Ashton, G. C., ANd A. W. Braden. 1961. Serum $\beta$-globulin polymorphism in mice. Aust. J. Biol. Sci. 14: 248-253.

Bartlett, M.S., and J. B. S. Haldane. 1935. The theory of inbreeding with forced heterozygosis. J. Genet. 31 : 327-340.

BERRY, R. J. 1963. Epigenetic polymorphism in wild populations of Mus musculus. Genet. Res., Cambridge 4: 193-220.

- 1964. The evolution of an island population of the house mouse. Evolution 18: 468483.

Brown, R. Z. 1953. Social behavior, reproduction and population changes in the house mouse (Mus musculus, L.), Ecol. Monogr. 23: $217-240$.

Conen, B. L. 1960. Genetics of plasma transferrins in the mouse. Genet. Res., Cambridge 1: $431-438$.

Cotterman, C. W. 1954. Estimation of gene frequencies in nonexperimental populations, Chapt. 35, p. 449-465. In O. Kempthorne, T. A. Bancroft, J. W. Gowen, and J. L. Lush [eds.] Statistics and mathematics in biology. lowa State College Press, Ames.

Crowcroft, P., and F. P. Rowe. 1963. Social organization and territorial behaviour in the wild house mouse (Mus musculus L.). Proc. Zool. Soc. Lond. 140: 517-531.

DeoL, M. S. 1958. Genetical studies on the skeleton of the mouse. XXIV. Further data on skeletal variations in wild populations. $J$. Embry. Exp. Morph. 6: 569-574.

DunN, L. C. 1957a. Evidence of evolutionary forces leading to the spread of lethal genes in wild populations of house mice. Proc. Nat. Acad. Sci. U.S. 43: 158-163. 
1957b. Studies of genetic variability in populations of wild house mice. II. Analysis of eight additional alleles at locus $T$. Genetics 42: 299-311.

Dunn, L. C., AND J. Suckling. 1956. Studies of genetic variability in populations of wild house mice. I. Analysis of seven alleles at locus $T$. Genetics 41 : 344-352.

Engles, W. L. 1948. White-bellied house mice. J. Hered. 39: 94-96.

Evans, F. C. 1949. A population study of house mice (Mus musculus) following a period of local abundance. J. Mammal. 30: 351-363.

Fisher, R. A. 1958. The genetical theory of natural selection. Second ed. Dover Publications, New York.

Gluecksohn-Waelsch, S., H. M. Ranney, AND B. F. SisK 5 N. 1957. The hereditary transmission of hemoglobin differences in mice. $\mathrm{J}$. Clin. Invest. 36: 753-756.

GruneberG, H. 1952. The genetics of the mouse. Martinus Nijhoff, The Hague.

Hutton, J. J., J. Bishop, R. Schweet, and E. S. RUSSELL. 1962. Hemoglobin inheritance in inbred mouse strains. I. Structural differences. Proc. Nat. Acad. Sci. U.S. 48: 1505-1513.

Justice, K. E. 1962. Ecological and genetical studies of evolutionary forces acting on desert populations of Mus musculus. Arizona-Sonora Desert Museum Inc., Tucson, Arizona.

Kempthorne, O. 1957. An introduction to genetic statistics. John Wiley \& Sons, New York.

Lewontin, R. C., And L. C. Duns. 1960. The evolutionary dynamics of a polymorphism in the house mouse. Genetics 45: 705-722.

LI, C. C. 1955a. The stability of an equilibrium and the average fitness of a population. Amer. Natur. 89: 281-296.

1955b. Population genetics. The University of Chicago Press, Chicago.

LI, C. C., ANd D. G. Horwitz. 1953. Some methods of estimating the inbreeding coefficient. J. Human Genet. 5: 107-117.

Linduska, J. P. 1942. Ecology and land-use relationships of small mammals on a Michigan farm. Game Div. Publ., Lansing, Mich., 144 p.

Markert, C. L., and R. L. Hunter. 1959. The distribution of esterases in mouse tissues. J. Histochem. Cytochem. 7: 42-49.

Neel, J. V., and W. J. Schull. 1954. Human heredity. Univ. Chicago Press, Chicago.

Petras, M. L. 1963. Genetic control of a serum esterase component in Mus musculus. Proc. Nat. Acad. Sci. U.S. 50: 112-116.

- 1965. Polymorphisms in natural populations of the house mouse, Mus musculus. Ph.D. Dissertation, Univ. Michigan, Ann Arbor.

Petras, M. L., M. F. Singer, and M. Foster. 1964. Blood group variations in natural populations of the house mouse, Mus musculus. Genetics 50: 276.

Petrusewicz, K., and R. Andrzejewski. 1962.
Natural history of a free-living population of house mouse (Mus musculus Linnaeus) with particular reference to groupings within the population. Ekologia Polska Seria A 10: 85122.

Philip, U. 1938. Mating system in wild populations of Dermetes vulpines and $M u s$ musculus. J. Genet. 36: 197-211.

Popp, R. A., ANd D. M. Popp. 1962. Inheritance of serum esterase having different electrophoretic patterns. J. Hered. 53: 111-114.

Popp, R. A., And W. St. Amand. 1960. Studies on the mouse hemoglobin locus. I. Identification of hemoglobin types and linkage of hemoglobin with albinism. J. Hered. 50: 141144.

Ranney, H. M., and S. Gluecksohn-Waelsch. 1955. Filter-paper electrophoresis of mouse haemoglobin: Preliminary note. Ann. Human Genet. 19: 269-272.

Rasmussen, D. I. 1962. Antigenic polymorphism in Peromyscus maniculatus gracilis. Ph.D. Dissertation, Univ. Michigan, Ann Arbor.

1964. Blood group polymorphism and inbreeding in natural populations of the deer mouse Peromyscus maniculatus gracilis. Evolution 18: 219-229.

Rowe, F. P., E. J. Taylor, and A. H. J. Chudley. 1963. The numbers and movements of housemice (Mus musculus L.) in the vicinity of four corn-ricks. J. Anim. Ecol. 32: 87-97.

Russell, E. S., ANd P. S. Gerald. 1958. Inherited electrophoretic hemoglobin patterns among 20 inbred strains of mice. Science 128: 1569-1570.

Shreffler, D. C. 1960. Genetic control of serum transferrin type in mice. Proc. Nat. Acad. Sci. U.S. 46: 1378-1384.

Southern, H. N., ANd E. M. Laurie. 1946. The house mouse in corn ricks. J. Anim. Ecol. 15: 134-149.

WebEr, W. 1950. Genetical studies on the skeleton of the mouse. III. Skeletal variations in wild populations. J. Genet. 50: 174-178.

Wright, S. 1921. Systems of mating. Genetics 6: $111-178$.

- 1940. Breeding structure of populations in relation to speciation. Amer. Natur. 84: 232248.

- 1943. Isolation by distance. Genetics 28 : 114-138.

1949. Population structure in evolution. Proc. Amer. Phil. Soc. 93: 471-478.

1951. The genetical structure of populations. Ann. Eugen. 15: 323-354.

1956. Modes of selection. Amer. Natur. $90: 5-24$.

Young, H., R. L. Strecker, and J. T. EmLen. 1950. Localization of activity in two indoor populations of house mice, Mus musculus. J. Mammal. 31 : 403-410. 